\title{
Design de produto médico-hospitalar: projeto e desenho | coletor de urina sistema fechado para perna
}

Andréia Bordini de Brito (Currículo Lattes)

Uda Souza Fialho (Currículo Lattes)

José Fialho de Oliveira Júnior (Currículo Lattes)

\section{A ÁREA DE PRODUTOS MÉDICO-HOSPITALARES NO BRASIL: COLETOR DE URINA SISTEMA FECHADO PARA PERNA}

A água que circula no organismo é resultado da ingestão de líquidos e alimentos sólidos e dos processos metabólicos de oxidação. Ainda que o excesso de água seja eliminado pela pele, pulmões e sistema gastrointestinal, o sistema urinário é o principal responsável pela eliminação da água do organismo. O processo de eliminação da urina envolve reflexos inconscientes e comandos voluntários. Quando a bexiga enche, os receptores da sua parede mandam a mensagem ao cérebro de que a urina precisa ser eliminada, provocando o desejo 
de urinar. Para que esse processo ocorra de maneira efetiva são necessários vários elementos, como os nervos que levam a mensagem dos receptores da parede da bexiga até o cérebro, a função cerebral para inibir o reflexo, os nervos que irão enviar a mensagem de inibição e os músculos envolvidos no processo de reter e eliminar a urina, como os do assoalho pélvico e o esfíncter uretral.

A falha de algum desses elementos pode comprometer 0 funcionamento do sistema urinário de forma transitória e facilmente tratável ou de forma duradoura ou permanente, afetando indivíduos de qualquer idade ou nível sócioeconômico. Para solucionar os diversos problemas no trato urinário, pode-se citar, de forma geral, medidas não invasivas, empregadas na tentativa de estimular a micção, ou medidas invasivas, em que há inserção de uma sonda para esvaziamento da bexiga. A sondagem ou cateterismo vesical é um exemplo de medida invasiva que tem por finalidade a remoção da urina por meio da inserção de uma sonda ${ }^{1}$ ou cateter $^{2}$ na bexiga, através da uretra ou por via suprapúbica.

As causas que levam uma pessoa à necessidade da sondagem vesical são variadas, como situações cirúrgicas (antes, durante e após a cirurgia), incontinência urinária, obstrução da saída da bexiga, entre outras (GOULD, 2009). As sondas podem ser inseridas por um curto período de tempo e removidas logo após o uso (sondas de alívio) ou mantidas no local no período de dias ou mais (sondas de demora), quando há a necessidade de sua permanência.

A sonda de alívio pode ser utilizada para drenar uma bexiga distendida, obter uma amostra de urina estéril, medir a urina residual ou esvaziar a bexiga antes da cirurgia. Enquanto a sonda de demora

\footnotetext{
${ }^{1}$ Tubo que se introduz em canal do organismo, natural ou não para reconhecer-lhe o estado, extrair ou introduzir algum tipo de matéria.

${ }^{2}$ Instrumento tubular que é inserido no corpo para retirar líquidos, introdu-zir sangue, soro, medicamentos e efetuar investigações diagnósticas
} 
é usada para propiciar drenagem vesical contínua ou alternada, introduzir gota a gota uma substância medicamentosa ou líquidos para irrigação, monitorar e contornar a produção de urina dos pacientes (ATKINSON; MURRAY, 1989); assim, as sondas de demora possuem saída dupla: uma saída tem a finalidade de drenar a urina, e a outra serve para inflar o balão próximo à extremidade da sonda, que a mantém presa no interior da bexiga.

Nesse contexto, o tempo de permanência da cateterização vesical é o fator decisivo para o surgimento de infecções (ANVISA, 2013). Conforme apontam Mike e Tambyah (2001), a contaminação por bactérias pode ocorrer durante a inserção do cateter ou posteriormente quando as bactérias ascendem pela superfície externa do cateter (Contaminação Extraluminal) ou quando há refluxo de micro-organismos que estão na bolsa de urina (Contaminação Intraluminal) devido à falha do sistema de drenagem fechada ou pela urina contida na bolsa. Dessa forma, as sondas de demora devem ser utilizadas com um sistema fechado de drenagem urinária, que permite a introdução de uma solução sem a abertura do sistema, reduzindo assim o risco de infecção.

No sistema fechado de drenagem urinária, também conhecido como coletor de urina sistema fechado, a urina que se encontra na bexiga flui através da sonda para a bolsa coletora devido à ação da gravidade (método de drenagem direta). Sua estrutura é composta por uma sonda ou cateter de demora, um tubo de conexão e uma bolsa coletora, que é esvaziada através de uma válvula de saída. Os coletores de urina podem ser classificados em dois grandes grupos:

I) Coletor de urina sistema fechado (Figura 1): possui capacidade para maiores volumes de urina (por volta de $2.000 \mathrm{ml}$ ) e é utilizado em leitos hospitalares e domésticos, geralmente suspenso na cama do paciente. 
II) Coletor de urina sistema fechado para perna (Figura 2): possui capacidade para volumes pequenos (em torno de $500 \mathrm{ml}$ ) e fica localizado por baixo da roupa, fixo à perna do usuário por meio de correias, permitindo seu deslocamento para a realização de atividades ao longo do dia.

Figura 1 - Coletor de urina sistema fechado para leito

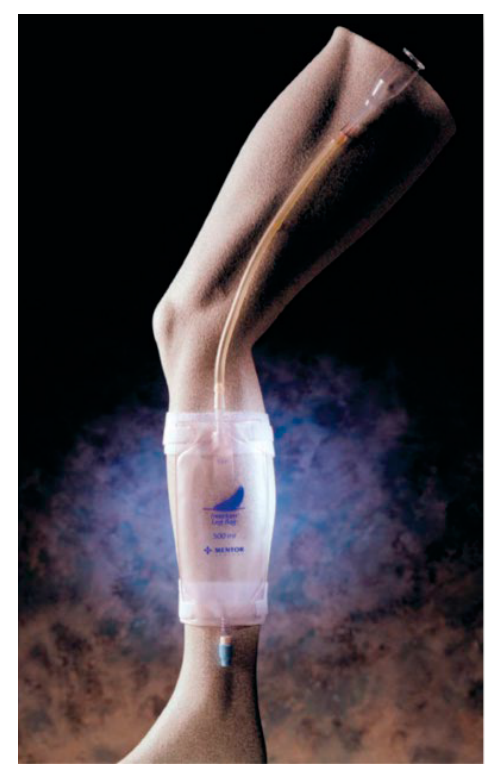

Fonte: www.medscape.com
Figura 2 - Coletor de urina sistema fechado para perna

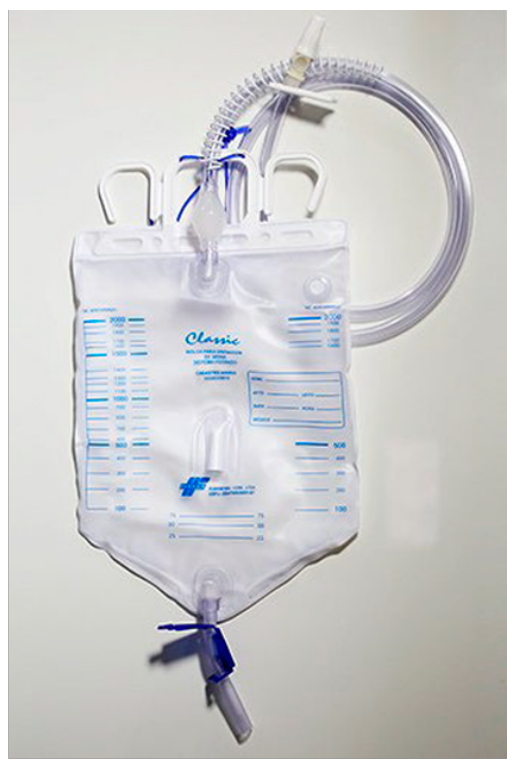

Fonte: www.flexor.ind.br

As pessoas utilizam o coletor de urina para perna, principalmente, devido a problemas de saúde que ocasionaram incontinência urinária. Contudo, essas pessoas buscam conduzir sua rotina da forma mais natural possível, realizando as atividades diárias de forma segura e confortável. De acordo com Cottenden (2009), o desafio para as pessoas que possuem incontinência urinária é descobrir a forma de lidar com esse problema para que os impactos causados na sua qualidade de vida sejam mínimos. Isso envolve a utilização 
de um produto que aja no controle da continência, na contenção de vazamentos de urina ou no gerenciamento da retenção urinária.

A empresa $X$ atua no setor de produtos médico-hospitalares e desenvolve, entre outros produtos, uma linha descartável de coletores de urina sistema fechado para leitos de hospitais, destinada ao público adulto e infantil. A empresa identificou que os coletores de urina para perna existentes no mercado apresentam-se similares e não indicam que há uma busca por melhorias no produto para atender e acompanhar o estilo de vida dos usuários. Assim, a empresa $X$ propôs o desenvolvimento desse produto, buscando atender à demanda do âmbito de mercado em que atua. $O$ objetivo deste estudo foi desenvolver um coletor de urina sistema fechado para perna, disponibilizando ao mercado um produto que atenda melhor às necessidades do usuário em termos funcionais, estéticos e simbólicos.

\section{PROCESSO DE DESENHO PROJETUAL: FASES DO PROJETO PARA DESENHO DE PRODUTO MÉDICO-HOSPITALAR}

O levantamento de dados e as análises foram realizados com a utilização de produtos cedidos pela empresa, de produtos encontrados no mercado e de buscas na internet. As análises, baseadas nos subsistemas do produto, foram realizadas para conhecer a estrutura, as funções, a ergonomia, os atributos semânticos e estéticos, entre outras características dos coletores de urina analisadas em função do público-alvo em questão. As técnicas utilizadas foram documentação/análise fotográfica, desenhos esquemáticos e estruturais e prototipagem rápida. 


\section{Análise denotativa e conotativa}

Conforme Brito (2004, p. 6), "as técnicas de análise denotativa e conotativa dizem respeito ao reconhecimento de termos, expressões e conceitos relacionados com o tema projetual". A análise denotativa (Figura 3) aborda os significados literários, contidos em dicionários, compêndios e afins, que independem do contexto em questão. Enquanto a conotativa (Figura 3) busca os significados que as coisas vão adquirindo ao longo do tempo, realizada por meio de revisão literária; o significado está ligado a um contexto específico. A análise denotativa foi realizada com as palavras coletor e bolsa, que não estão ligadas ao contexto específico, e sim à função de armazenamento. Para a conotativa, considerou-se o termo bolsa de drenagem urinária, inserido no contexto do problema estudado.

Figura 3 - Análise denotativa e conotativa

\begin{tabular}{|c|c|c|c|}
\hline & \multicolumn{3}{|c|}{ Análise denotativa } \\
\hline & Aurélio & Larousse & Michaelis \\
\hline$\stackrel{\mathscr{D}}{\circ}$ & $\begin{array}{l}\text { 1. Cavidade que contém secreção, ou outro } \\
\text { fluido. 2. Bolsa de colostomia. Recipiente } \\
\text { destinado a coletar matéria fecal eliminada } \\
\text { através de colostomia. }\end{array}$ & $\begin{array}{l}\text { 1. Saco de pequena dimensão, } \\
\text { selado, para embalar produtos } \\
\text { líquidos ou pastosos. }\end{array}$ & $\begin{array}{l}\text { 1. Recipiente de pano, couro ou matéria } \\
\text { plástica, cuja boca possui, às vezes, um } \\
\text { sistema qualquer de fechamento, como } \\
\text { ziper, botöes etc. }\end{array}$ \\
\hline \multirow[t]{2}{*}{$\frac{\bar{g}}{\mathrm{o}}$} & $\begin{array}{l}\text { 1. Que colige, compila, reúne. } 2 \text {. Diz-se de } \\
\text { cano principal de esgoto, ou de águas pluviais, } \\
\text { no qual se entroncam os canais secundários. }\end{array}$ & $\begin{array}{l}\text { 1. Todo recipiente em que se } \\
\text { juntam coisas. }\end{array}$ & $\begin{array}{l}\text { 1. Aparelho ou recipiente destinado a } \\
\text { recolher alguma substância. }\end{array}$ \\
\hline & \multicolumn{3}{|c|}{ Análise conotativa } \\
\hline$\frac{\sqrt[\pi]{\frac{\pi}{2}}}{2}$ & Weber et al. (2004) & Não identificado & Williams \&Wilkins \\
\hline 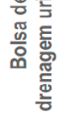 & $\begin{array}{l}\text { 1. Dispositivo pequeno que se adere à perna } \\
\text { mediante bandas elásticas. }\end{array}$ & $\begin{array}{l}\text { 1. Dispositivo utilizado para cortar } \\
\text { fluidos, é utilizada presa na perna. }\end{array}$ & $\begin{array}{l}\text { A bolsa de perna armazena menos urina } \\
\text { que a bolsa de drenagem (a que se usa } \\
\text { deitado), mas permite que a pessoa se } \\
\text { movimente com maior facilidade. }\end{array}$ \\
\hline
\end{tabular}

Fonte: elaborada pelos autores

\section{Análise diacrônica}

A análise diacrônica consiste na investigação da origem e evolução do produto em questão. Para a realização dessa análise foram tomados como referência os produtos desenvolvidos para 
incontinência urinária que possuem registros históricos, assim como mostra a Figura 4.

Figura 4 - Análise diacrônica

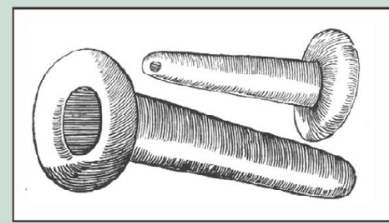

Artificial Yard, 1564

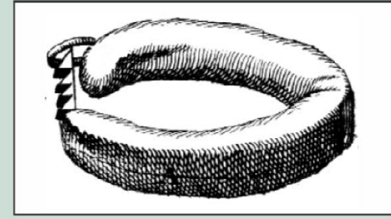

Pinça peniana, 1747

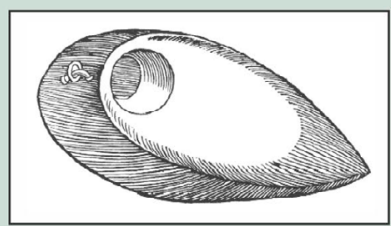

Urinol masculino, 1564

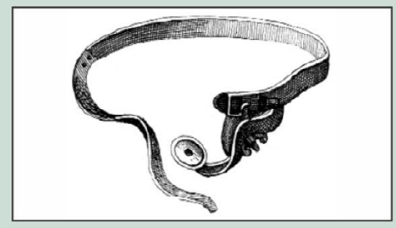

Cinto de compressão, 1747

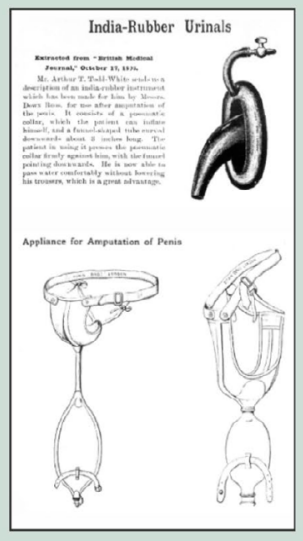

Catálogo, 1906

Fonte: elaborado pelos autores, baseada em Schultheiss (2009)

\section{Análise sincrônica}

O objetivo da análise sincrônica é conhecer e compreender o mercado onde o produto será inserido, possibilitando a descoberta de problemas em produtos concorrentes, que devem ser solucionados no novo produto; além disso, evita o desenvolvimento de um produto que já existe, proporcionando ao usuário um produto aperfeiçoado em relação aos disponíveis.

Lobach (2001) destaca que a análise comparativa de produtos deve representar o estado real dos produtos existentes, determinar suas deficiências e valores, para estabelecer a melhoria possível do produto em desenvolvimento. A Figura 5 apresenta os coletores de urina para perna cedidos pela empresa x para a realização da análise. Foram analisados sete coletores que possuem capacidade para 500 $\mathrm{ml}(2,3,5$ e 7$)$, para $750 \mathrm{ml}$ (4 e 6) e para $2.000 \mathrm{ml}(1)$. 
Figura 5 - Análise sincrônica

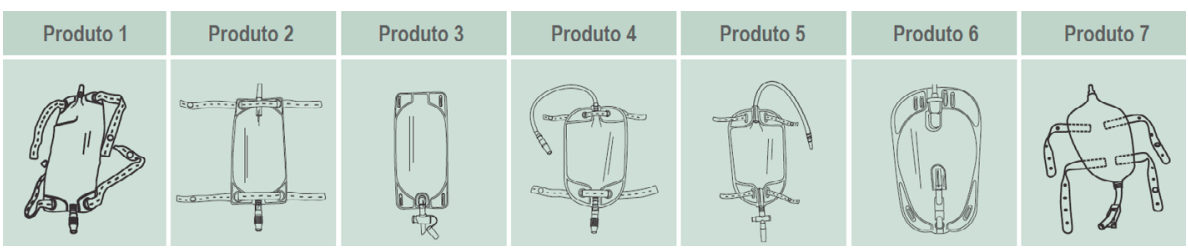

Fonte: elaborada pelos autores

A maioria dos coletores possui bolsas de PVC descartáveis e custa valores similares, com exceção do produto 7, que é feito de látex e é reutilizável, assim, possui custo mais alto em relação aos demais.

Os coletores apresentam pouca variação de cores, geralmente em tons frios. Embora as estruturas dos produtos sejam semelhantes entre si, pode-se destacar alguns componentes que exercem papel importante e, assim, estão presentes na estrutura do novo produto: o filtro de ventilação, a válvula antirrefluxo e o coldre protetor.

\section{Análise estrutural e funcional}

O objetivo das análises estrutural e funcional é reconhecer e compreender tipos e o número de componentes, subsistemas, princípios de montagem e tipologia das uniões, bem como os aspectos funcionais e de uso do produto que será desenvolvido (BONSIEPE, 1984).

Devido à semelhança estrutural dos coletores, essa análise teve como produto referência o coletor da marca Convatec (produto número 7 da análise sincrônica), considerado pela empresa $x$ aquele que possui as características mais próximas do desejado. Dessa forma, como mostra a Figura 6, a estrutura do coletor de urina para perna foi dividida em quatro subsistemas: (1) conector de sonda, (2) tubo extensor, (3) bolsa e (4) conector de saída, entre os quais alguns foram divididos ainda em subsubsistemas. 
A função principal do produto é armazenar a urina, cujo volume máximo é $500 \mathrm{ml}$. A função secundária do coletor de urina para perna é permitir a locomoção do usuário. A divisão dos subsistemas foi baseada na distribuição espacial dessas partes na estrutura como um todo e nas funções que exercem.

Figura 6 - Análise estrutural e funcional do coletor de urina para perna

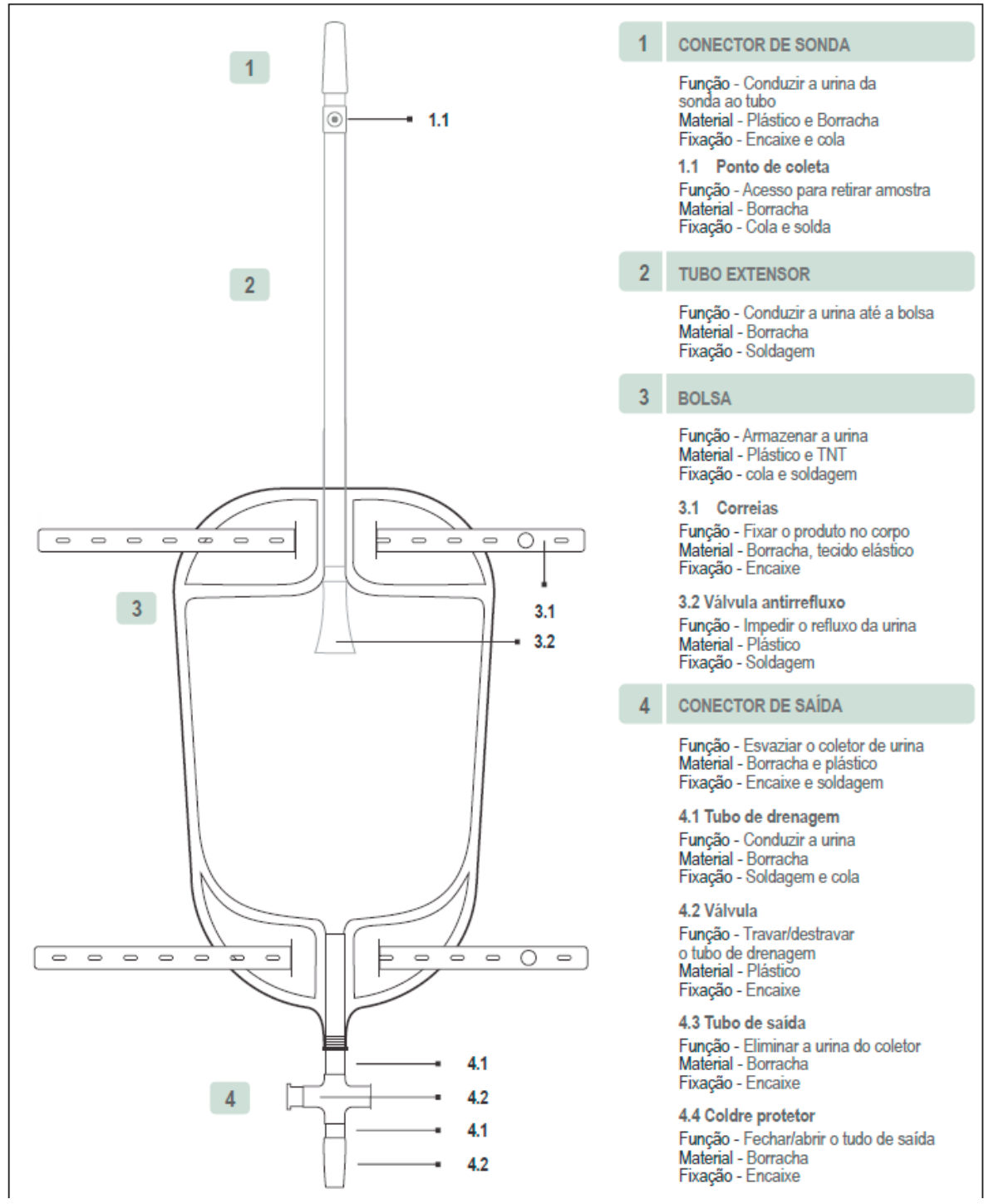

Fonte: elaborada pelos autores 


\section{Análise ergonômica}

Esta análise aborda requisitos de segurança, conforto e usabilidade do produto e possibilita a identificação das dificuldades do usuário ao utilizar o produto. A análise foi composta pela ordenação hierárquica das partes do produto (Figura 7), pela descrição da tarefa (Figura 8), pela definição das medidas antropométricas (Figura 9), pelo estudo de pegas e manejos (Figura 10) e pela definição dos requisitos e restrições da tarefa (Figura 11).

Figura 7 - Ordenação hierárquica

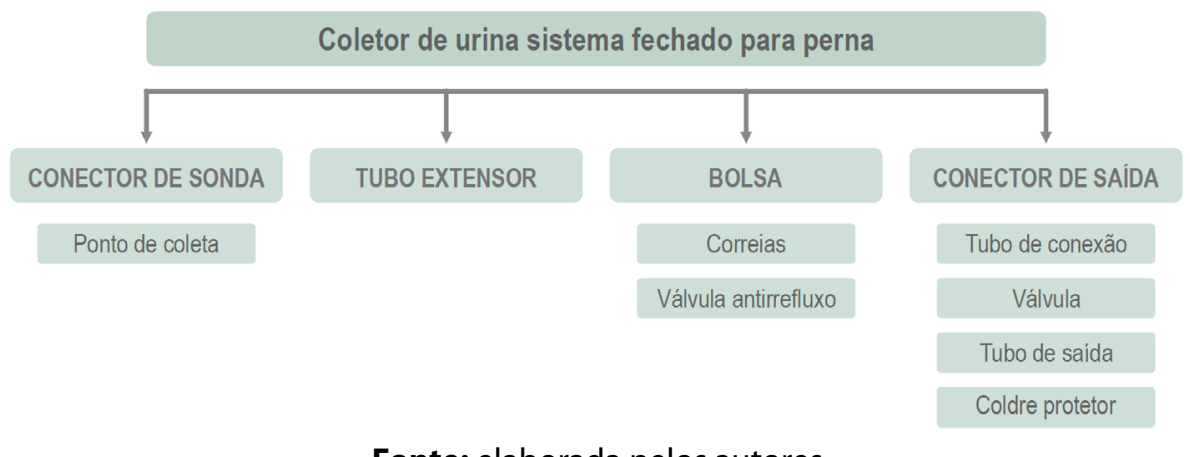

Fonte: elaborada pelos autores

Figura 8 - Descrição da tarefa

Objetivo
Utilização do coletor com
a finalidade de armazenar
a urina e permitir fáceis
locomoção e manuseio
para o usuário.

\section{Operadores}

Homens e mulheres, sem faixa etária especifica, com problemas no sistema urinário (retenção ou incontinência urinária).

\section{Condições operacionais}

O operador utiliza o produto realizando ações sentado ou em pé. O desconforto acontece porque o local onde o coletor fica acoplado (perna) fica longe dos membros que controlam seu uso - as mãos, forçando o usuário a dobrar o corpo para manuseá-lo.

Fonte: elaborada pelos autores

As dimensões do produto foram determinadas conforme as medidas antropométricas de homens e mulheres (Figura 9) de percentil 99, que abrange $99 \%$ da população. O tamanho do tubo extensor foi 
definido conforme o percentil 1, pois, como é fixo à perna, deve abranger desde o mínimo ao máximo tamanho.

Figura 9 - Medidas antropométricas

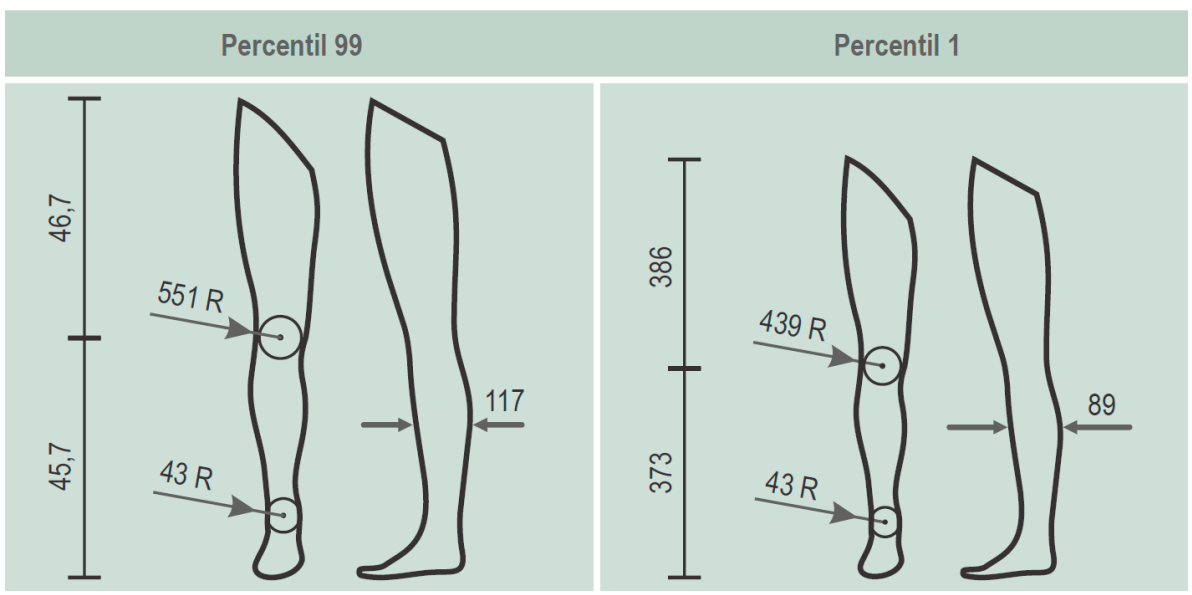

Fonte: elaborada pelos autores, baseada em Dreyfuss (2005)

Figura 10 - Análise de pegas e manejos

1 Acessar o coletor

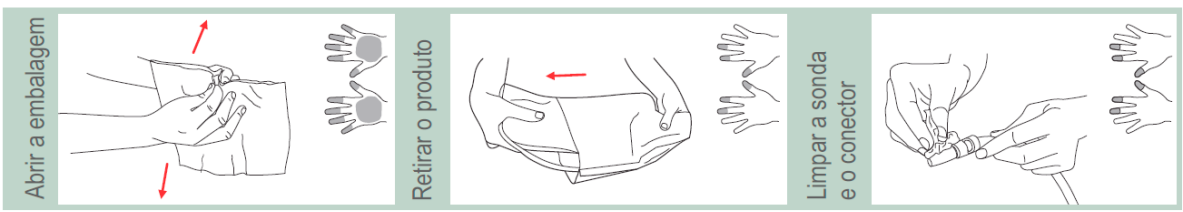

2 Vestir o coletor

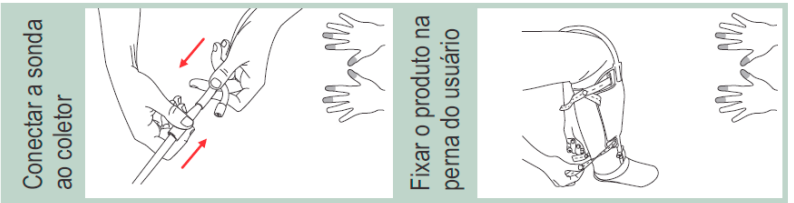

3 Esvaziar o coletor

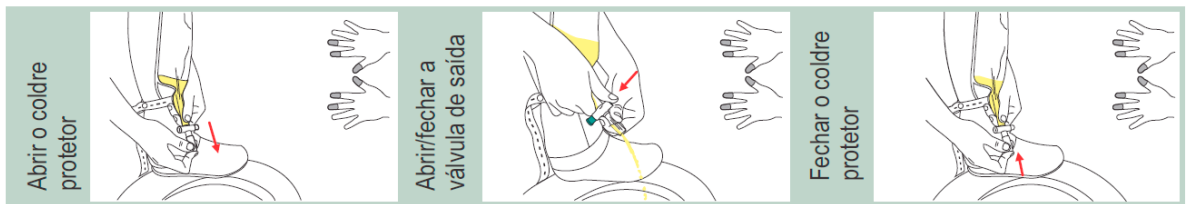

Fonte: elaborada pelos autores 
Os requisitos e restrições da tarefa (Figura 11) determinam, consecutivamente, o que o produto deve possuir para que a tarefa seja realizada com conforto e segurança pelo usuário e os fatores que podem dificultar a obtenção do produto ergonomicamente ideal.

Figura 11 - Requisitos e restrições da tarefa

\begin{tabular}{|c|c|}
\hline Requisitos & Restrições \\
\hline $\begin{array}{l}\text { - Aestrutura deve ter capacidade para } 500 \mathrm{ml} \text {. } \\
\text { - O produto deverá possuir uma estrutura que distribua de } \\
\text { maneira uniforme a urina, e que se mantenha estável com o } \\
\text { passar do tempo durente o uso do produto. } \\
\text { - As correias deverão ser reguláveis e antitranspirantes; } \\
\text { não devem provocar escaras, beliscões, nem problemas de } \\
\text { circulação e transferência de calor. } \\
\text { - O material deverá ser hipoalergênico; manter a } \\
\text { temperatura constante quando a urina é armazenada na } \\
\text { bolsa; impedira passagem de odor e vazamentos. } \\
\text { - o produto deverá ser adequado as medidas } \\
\text { antropométricas referenteao percentil } 97 \text {. } \\
\text { - O conector de saida deverá ser protegido do meio } \\
\text { externo. }\end{array}$ & $\begin{array}{l}\text { O material não ser de boa qualidade e desfavorecer a } \\
\text { estabilidade da bolsa. } \\
\text { - As correias causarem algum tipo de lesão para os } \\
\text { usúarios. } \\
\text { - A válvula de saída não vedar totalmente ocasionando } \\
\text { vazamentos. } \\
\text { - O conector de saída ficar exposto ao meio externo e } \\
\text { contaminarousuário. } \\
\text { - O material causaralergias ao usuário. } \\
\text { medidas antropométricas limitando os movimentos do } \\
\text { usuário. }\end{array}$ \\
\hline
\end{tabular}

Fonte: elaborada pelos autores

\section{Análise morfológica}

Os coletores possuem baixa complexidade em relação à forma. Como mostra a Figura 12, os coletores foram separados em dois grupos que diferem, basicamente, pela forma da bolsa -parte principal da estrutura, cuja configuração apresenta visíveis elementos geométricos, simetria, bidimensionalidade e leitura no sentido vertical. O primeiro grupo caracteriza-se por possuir estrutura retangular com arestas definidas, enquanto o segundo apresenta bordas arredondadas que deixam a estrutura mais orgânica em relação ao primeiro grupo. 
Figura 12 - Análise morfológica

GRUPO 1 | Produtos 1, 2 e 3

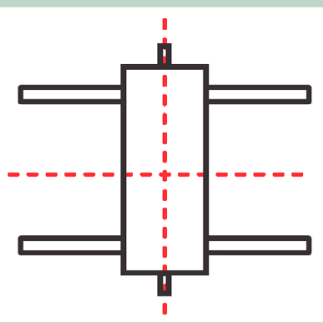

GRUPO 2 | Produtos 4, 5, 6 e 7

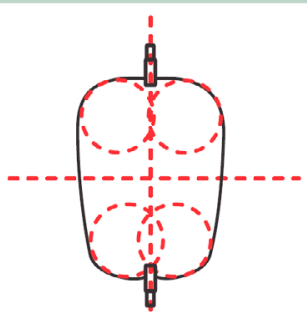

Fonte: elaborada pelos autores

\section{Análise da relação social, econômica e cultural do usuário e produto}

O público-alvo do produto abrange homens e mulheres que possuem algum problema no funcionamento do sistema urinário que levou à incontinência urinária. Os usuários podem apresentar ainda problemas no sistema neurológico que tenha afetado a locomoção. O produto é distribuído por hospitais e também pode ser adquirido em lojas de produtos médico-hospitalares. A Figura 13 apresenta produtos que indicam o estilo de vida do usuário, e a Figura 14 mostra diferentes representações físicas de possíveis usuários do coletor de urina para perna.

Figura 13 - Representação de produtos do usuário

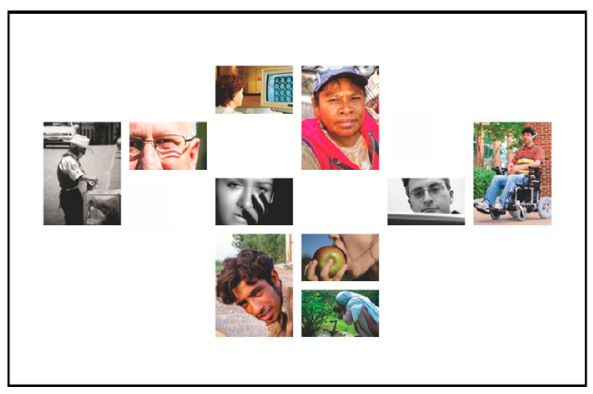

Fonte: elaborada pelos autores
Figura 14 - Representação do público-alvo

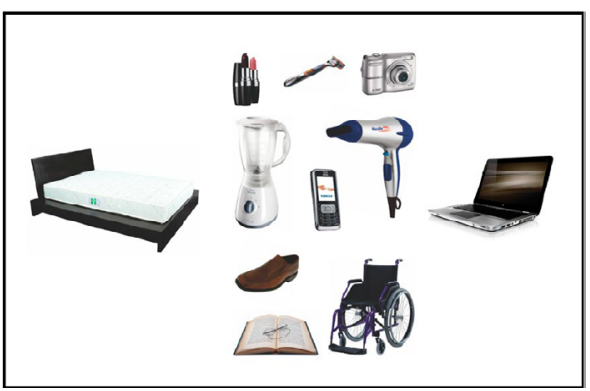

Fonte: elaborada pelos autores 


\section{Diretrizes do projeto}

Figura 15 - Diretrizes para o desenvolvimento do coletor de urina sistema fechado para perna

\begin{tabular}{|c|c|c|c|}
\hline ஜ्) & $\begin{array}{l}\text { - Utilizar correias que regulem. } \\
\text { - Utilizar a válvula de saída que obteve melhor } \\
\text { desempenho na análise da tarefa. }\end{array}$ & 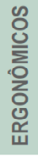 & $\begin{array}{l}\text { - Adequar as medidas antropométricas do percentil } 95 . \\
\text { - Possuir forma anatômica, adaptada à perna do usuário. }\end{array}$ \\
\hline 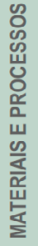 & $\begin{array}{l}\text { - Possuir materiais hipoalergênicos, isotérmicos e } \\
\text { impermeáveis. } \\
\text { - O conector de sonda, o tubo extensor e a válvula } \\
\text { de saida serão os determinados pela empresa X. } \\
\text { - Utilizar processos de fabricação, já presentes na } \\
\text { produção da empresa } X \text {, que vedem totalmente as } \\
\text { partes e as suas junçôes. }\end{array}$ & 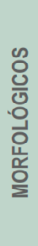 & $\begin{array}{l}\text { - As transições deverão ser cilindricas de modo que } \\
\text { conduzam a urina pelo coletor. } \\
\text { - Apresentar cores que transmitam sensação de limpeza. } \\
\text { - As partes serão configuradas de forma que a estrutura } \\
\text { final siga a orientação do corpo humano. }\end{array}$ \\
\hline 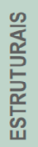 & $\begin{array}{l}\text { - A bolsa deverá possuir divisórias que } \\
\text { mantenham a urina distribuida uniformemente. } \\
\text { - O produto deverá conter todas as partes fixas a } \\
\text { sua estrutura principal. }\end{array}$ & 总 & $\begin{array}{l}\text { - Utilizar símbolos que indiquem como o produto } \\
\text { será utilizado. } \\
\text { - O conector de saída deverá possuir indicação de } \\
\text { uso. }\end{array}$ \\
\hline
\end{tabular}

Fonte: elaborada pelos autores

\section{REALIZAÇÃO DO PROJETO DE PRODUTO MÉDICO-HOSPITALAR: DESENVOLVIMENTO DO COLETOR DE URINA PARA PERNA}

Foram realizadas as seguintes atividades durante o processo criativo:

Primeiramente foram feitos rabiscos desordenados em busca de novas formas-técnica conhecida por graforrismo que gerou vários módulos utilizados posteriormente nos conceitos; as operações elementares de desenho estavam presentes na geração de algumas alternativas (Figuras 16 e 17). Em seguida foram buscados na natureza animais com estrutura semelhante ao do coletor de urina; essas estruturas foram decompostas em formas básicas - círculos, quadrados e triângulos-para assim originar novas formas, que são os conceitos e suas variações (Figuras 18). 
Figura 16 - Desenvolvimento do conceito 1
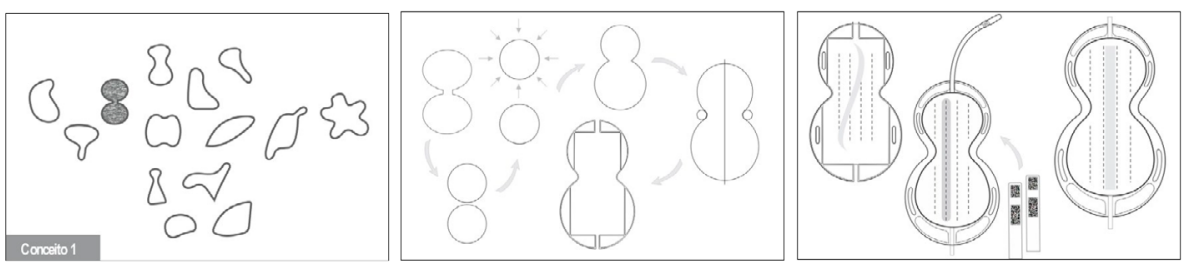

Fonte: elaborada pelos autores

Figura 17 - Desenvolvimento do conceito 2
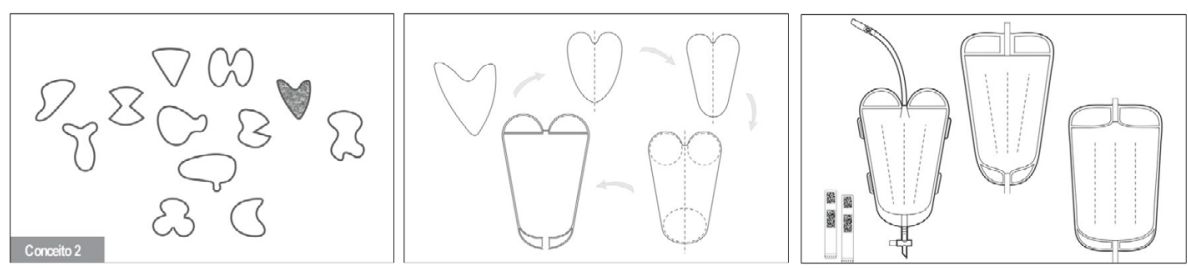

Fonte: elaborada pelos autores

Figura 18 - Desenvolvimento do conceito 3

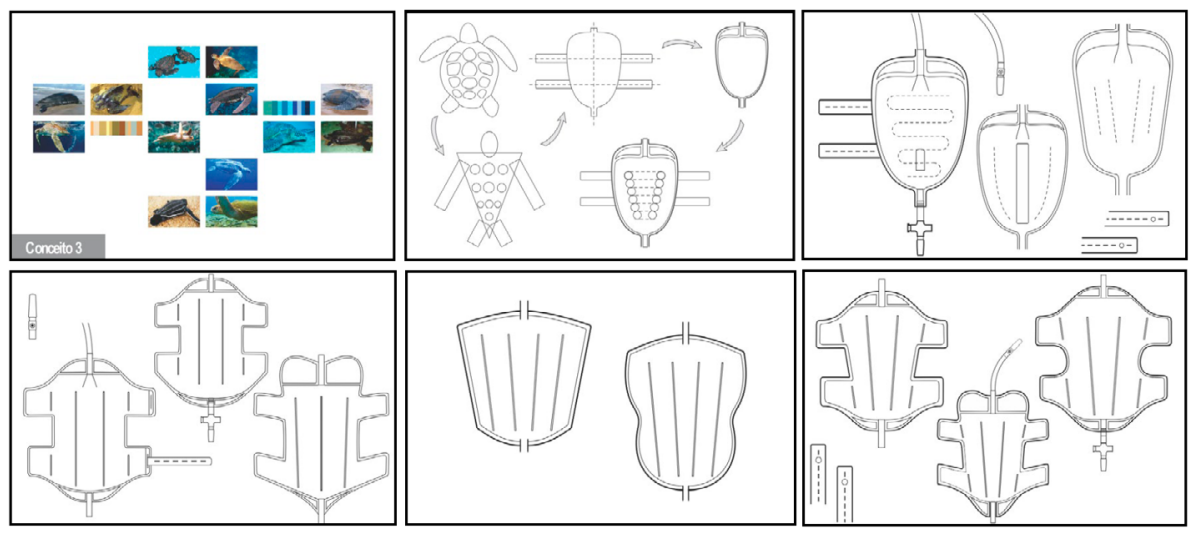

Fonte: elaborada pelos autores

Foi realizada uma pesquisa com profissionais da área de física para entender a ação da gravidade e o equilíbrio das forças atuantes 
para que o produto fosse deslocado o mínimo possível durante o uso. Também pelo fato do produto ser considerado um sistema de vasos comunicantes (i.e. recipiente formado por diversos ramos que se comunicam), foi preciso verificar qual o espaço mínimo entre os vasos para que a urina pudesse ser distribuída igualmente pela bolsa.

Após gerar algumas formas foi necessário testar os volumes para confirmação dos cálculos realizados por meio de fórmulas de volumes cilíndricos e tronco de cone. Os conceitos foram desenhados em tamanho real e em seguida foram produzidos modelos de plástico para teste do volume, simulando as formas das bolsas com as soldas. Os testes também possibilitaram observar o comportamento das soldas e a reação da estrutura com a entrada de água e definir o espaço para a comunicação das partes divididas pelas soldas. Foi produzido um modelo antropométrico (perna de isopor), com medidas do percentil 99, para observar a localização da bolsa na perna do usuário e testar os tamanhos limites.

\section{Conceito escolhido}

O conceito 3 foi selecionado por apresentar o maior número de características pertinentes aos requisitos do projeto. $O$ conceito foi fundamentado na biomimética a partir do estudo de formas e outros aspectos da natureza, que serviram de inspiração para o desenvolvimento do projeto. Considerando que a estrutura do produto é semelhanteà maioria dos animais quadrúpedes, o ambiente marinho foi selecionado para delimitar as espécies envolvidas. Em seguida, foram buscados os significados de alguns desses animais. Observou-se que os significados atribuídos a tartarugas-estabilidade, longevidade, paciência e resistência-eram coerentes tanto em relação ao produto quanto ao usuário. Assim, a tartaruga foi selecionada, e suas formas básicas-círculos, triângulos e quadrados, foram 
modificadas, originando a nova forma do coletor de urina e suas variações. Partindo do conceito 3, foram desenvolvidas alternativas, que evoluíram conforme os resultados dos testes volumétricos; assim, a variação 11 foi a estrutura selecionada (Figura 19).

Figura 19 - Conceito 3 variação 11

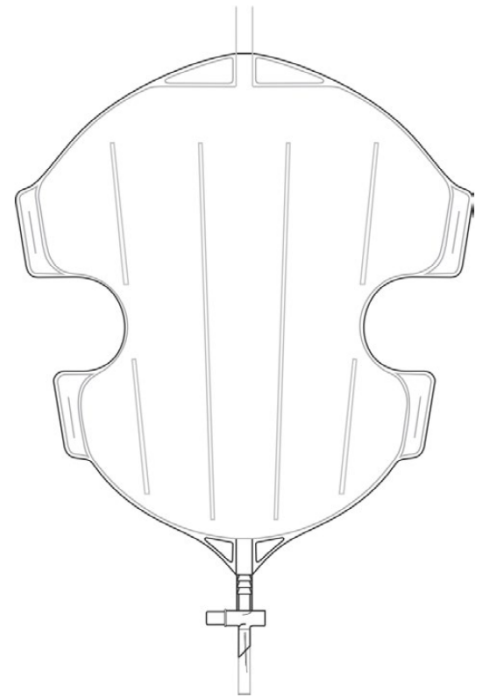

Fonte: elaborada pelos autores

A estrutura do conceito escolhido segue a mesma orientação do corpo humano, ou seja, orientação vertical com correias na direção horizontal, sendo a parte superior maior que a inferior, assim como a forma da perna humana. Possui formas e bordas arredondadas que atribui à estrutura configuração ergonômica, adaptando-se melhor ao corpo do usuário. $O$ conceito escolhido atende aos requisitos do projeto e apresenta o equacionamento dos fatores ergonômicos, perceptivos, tecnológicos e econômicos que determinam um produto bem solucionado.

Definiu-se que a bolsa deve possuir partes soldadas para melhor distribuir o líquido e evitar a dilatação da bolsa. Ao distribuir 
uniformemente o líquido (ver Figura 20), o usuário utilizará o produto com mais conforto, uma vez que o peso da urina será distribuído e diminuirá o deslocamento das correias. Como a bolsa pode dilatar-se até determinado ponto, será mais confortável para o usuário utilizála por baixo da calça, ficará menos perceptível. A parte frontal da bolsa é feita de PVC branco e possui uma área transparente para o monitoramento da urina.

As áreas soldadas da bolsa (Figura 20) solucionam importantes problemas detectados durante a análise da tarefa, no entanto, limitam o espaço que o líquido vai ocupar na bolsa, já que limitam a dilatação. Assim, as variações foram evoluindo de acordo com esse fator determinante. Durante o desenvolvimento das alternativas foram produzidos modelos para testar os espaços das bolsas, sendo necessário o espaço para volume de $500 \mathrm{ml}$.

Figura 20 - Conceito 3

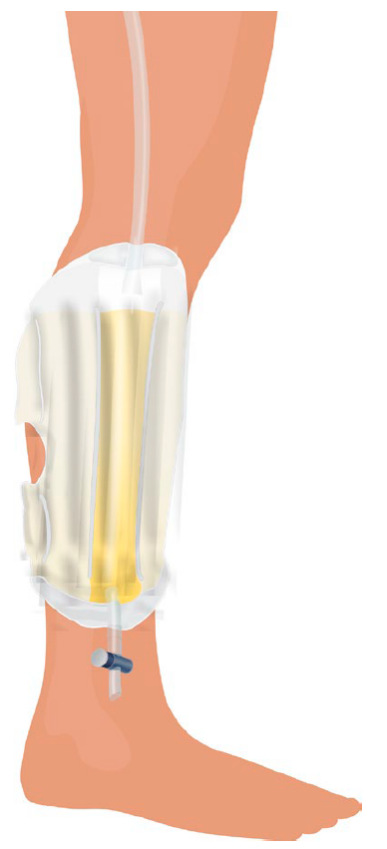

Fonte: elaborada pelos autores 
Pode-se perceber que nesse conceito a forma torna-se mais ergonômica, e também pelo fato do espaço ser maior que do que nas bolsas anteriores, já que o líquido pode ocupar ainda os espaços laterais.

Figura 21 - Modelo final do coletor de urina sistema fechado para perna

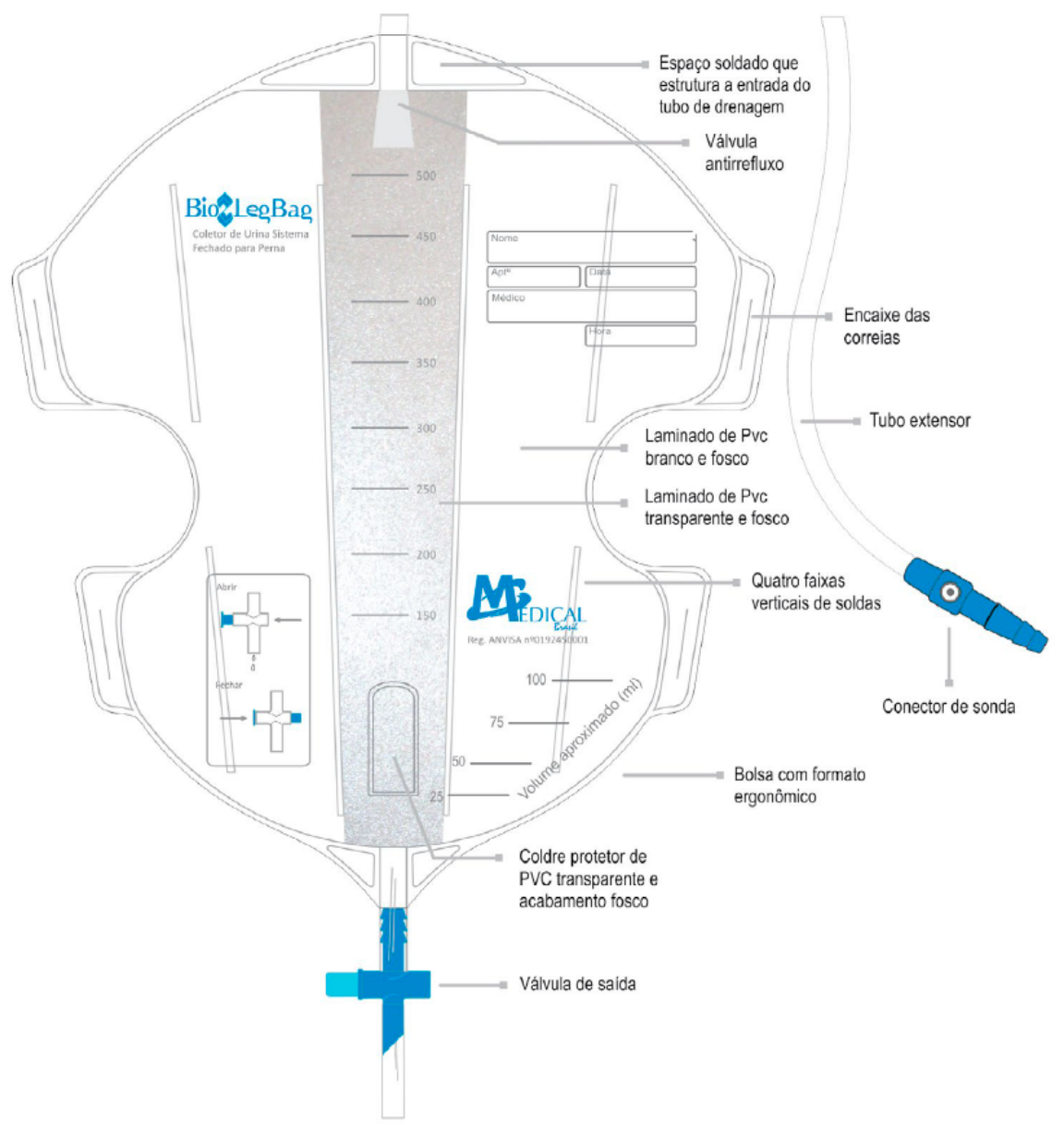

Fonte: elaborada pelos autores 


\section{REFERÊNCIAS}

ANVISA. Medidas de Prevenção de Infecção Relacionada à Assistência à Saúde. 2013. Disponível em: <http://www20.anvisa. gov.br/>. Acesso em: 14 mai. 2014.

Athikson e Murray. Fundamentos de Enfermagem: introdução ao Processo de Enfermagem. Rio de Janeiro: Guanabara, 1989.

BONSIEPE, G. Metodologia experimental - desenho industrial. Brasília: CNPQ/Coordenação Editorial, 1984.

BRITO, A. Ampliação do Vocabulário em Desenho Industrial: considerações para projeto de produto. 2004. 123 f. Dissertação (Mestrado em Engenharia de Produção) - Universidade Federal de Santa Maria, Rio Grande do Sul, 2004.

CONTTENDEN, A.; BLISS, D.; BUCKLEY, B.; FADER, M.; GETLIFFE, K.; PATERSON, J.; PIETERS, R.; WILDE, M. Management Using Continence Products, 2009, Paris. Proceedings... Paris: Editions 21, 2009.

DREYFUSS, Henry. As Medidas do Homem e da Mulher. Porto Alegre: Bookman, 2005.

GOULD, C.; UMSCHEID, C.; AGARWAL, R.; KUNTZM G.; PEGUES, D. The Healthcare Infection Control Practices Advisory Committee. 2009. Disponível em: <http://www.cdc.gov/>. Acesso em: mar. 2015.

LOBACH, Bernd. Diseño Industrial. Barcelona: Gustavo Gilli, 2001.

MAKI, D.; TAMBYAH, P. Engineering Out the Risk for Infection with Urinary Catheters. Emerging Infectious Diseases. [S. I.], v. 7, n. 2, p. 342-347, 2001. 
SCHULTHEISS, Dirk. A Brief History of Urinary Incontinence and its Treatment. Disponível em: <http://www.icsoffice.org $>$. Acesso em: 20 ago. 2014. 
